
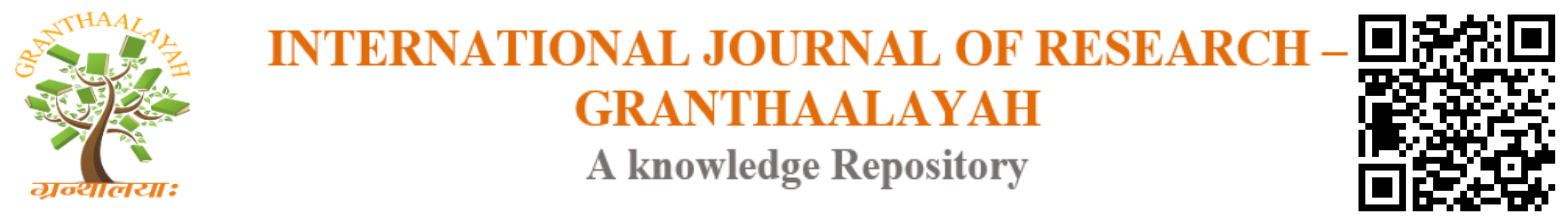

Management

\title{
FAILURE OF EMPLOYEE RETENTION AND ITS CONSEQUENCES ON ORGANISATION THROUGH CONTENT ANALYSIS
}

\author{
Archita Banerjee *1 \\ ${ }^{* 1}$ Research Scholar, Maulana Abul Kalam Azad University of Technology, India
}

\begin{abstract}
For any organization its workforce are the most valuable assets. Their implication to system describes not only the requirement to pull the best competence but also the need to hold on to them for a long term.

With evolution of globalization, competition is becoming keener and keener in most industries. These conditions affect the employment in the notion that companies insist on human capital to sustain in the market for a longer period of time. A proper retention strategy improves the performance of organisation in terms of product quality and profitability ratio.

The biggest challenge in current work scenario is how to engage people on the job as long as possible by carving a proper career path for them and shaping their future prospects in job.

The concept of employee retention is mainly motivating employees to stay in an association for a maximum period of time (Bidisha etal 2013). As Mita (2014) defined employee retention "is a tool accepted by companies to maintain an efficient fleet of workers and consecutively meet functional requirements Based on actual facts and findings, retaining the best employees makes sure client satisfaction, increase in product sales, peer satisfaction and effective succession planning. An entrenched organizational knowledge and learning which means, imparting proper training time and investment on regaining lost knowledge of employees, helps gaining back job security and a costly employee is won back. Thus, failing to which leads to a loss of important employees. A range of approximation suggests that losing a middle manager in most organizations costs up to five times his salary. Corporate were facing lot of problems in retention of employees these days. To hire well-informed people for the job is essential for an employer, but retention is even more important than hiring.
\end{abstract}

Keywords: Failure; Employee; Organisation.

Cite This Article: Archita Banerjee. (2019). "FAILURE OF EMPLOYEE RETENTION AND ITS CONSEQUENCES ON ORGANISATION THROUGH CONTENT ANALYSIS." International Journal of Research - Granthaalayah, 7(3), 200-207. https://doi.org/10.29121/granthaalayah.v7.i3.2019.960. 


\section{Introduction}

For any organisation employee turnover means the proportion of the organizational members who left at some stage divided by the average number of people in that organization during the same duration" (Price, 1977) it could be willfully or through compulsion but in both the cases it is harmful to the efficient operation of an organization.

Though there are some cases where organizations' could see a silver lining in precedence to this process as it opens up new opportunities of continuous standard employment ((Feldman, 1994). Though attrition seem to be a major problem hovering in IT companies on a continuous basis, but some companies could see opportunities generating from this process.

It indicates market is growing and offering a greater job opportunity with better profiles and compensation schemes (CXOtoday, 2014).SD Shibulal CEO of Infosys said that Attrition meant more Opportunities.

Manoj Bhat, Deputy Chief Financial Officer of Tech Mahindra agreed that due to Attrition wages keep increasing but their business model and recruiting model is proficient enough to manage the attrition problems (Simhan, 2014).

But this story might not always be true. Infosys has become a case-study by the analyst for any suggestion to find explanation on reduced sales and high attrition rates. This heads to the issue if retention problem is a symbol of business impetus. In a report of August 27, 2014 by JPMorgan tried to answer the question on Indian IT services.

In late 1990s, Fitz-enz (1990) experienced that employee loyalty and retention could not be judged by a sole issue but by a group of factors. There are studies which has identified multiple numbers of factors associated with retention issues. Through these studies it has been commonly found as cited by employees their dissatisfaction regarding developmental scopes and quality work life, stress at work place and peer pressure(Brown 2002); pay package and recognition, missing out challenges at work, vertical integration in career and amiable work culture, inter-personal relationships within workplace (Walker 2001) and relation with superior (Naqvi,2015).

As per Ghapanchi and Aurum (2011) most common factors of retention include pay benefits, scope for development, justified treatment, work culture. On the other hand Allen and Shanock (2013) emphasised on relationship with peer. Andrews and Wan (2009) focussed on leadership style to increase an organization retention capability. Christeen (2014) pointed eight factors of retention: entire system of management, amiable environment, peer support and developmental scope, authority of decision making, pay benefits, planned manpower, and quality work-life balance. Our analysis of individual factors is mainly based on the work.

In this paper, these factors have been rated by the respondents who are the regular employees to inorder to understand the level of parity between literature aspect and real life practice. 


\section{Literature Review}

The challenge of employee retention is worldwide. For instance in Saudi Arabian country, it is very important to keep a track on employee count for both Government and Private sectors. The disparity of pay in public and private sectors could be one of the reasons of dissatisfaction of employees hopping from one sector to another. Due to this fact Saudian Government has established a strict improvisation in recruitment policies. But this policy fails to retain employees as the owners feel employees are not serious or loyal towards their work or organisation (AlKahtani, 2002). Hence, recruitment plays a pivotal role in sustaining employees for a longer period of time. The star performers, who were identified during procurement process, were least susceptible to leave the organisation. The recipe for a proper recruitment process includes (Oracle Taleo Cloud Service). The recipe for a proper recruitment process includes:

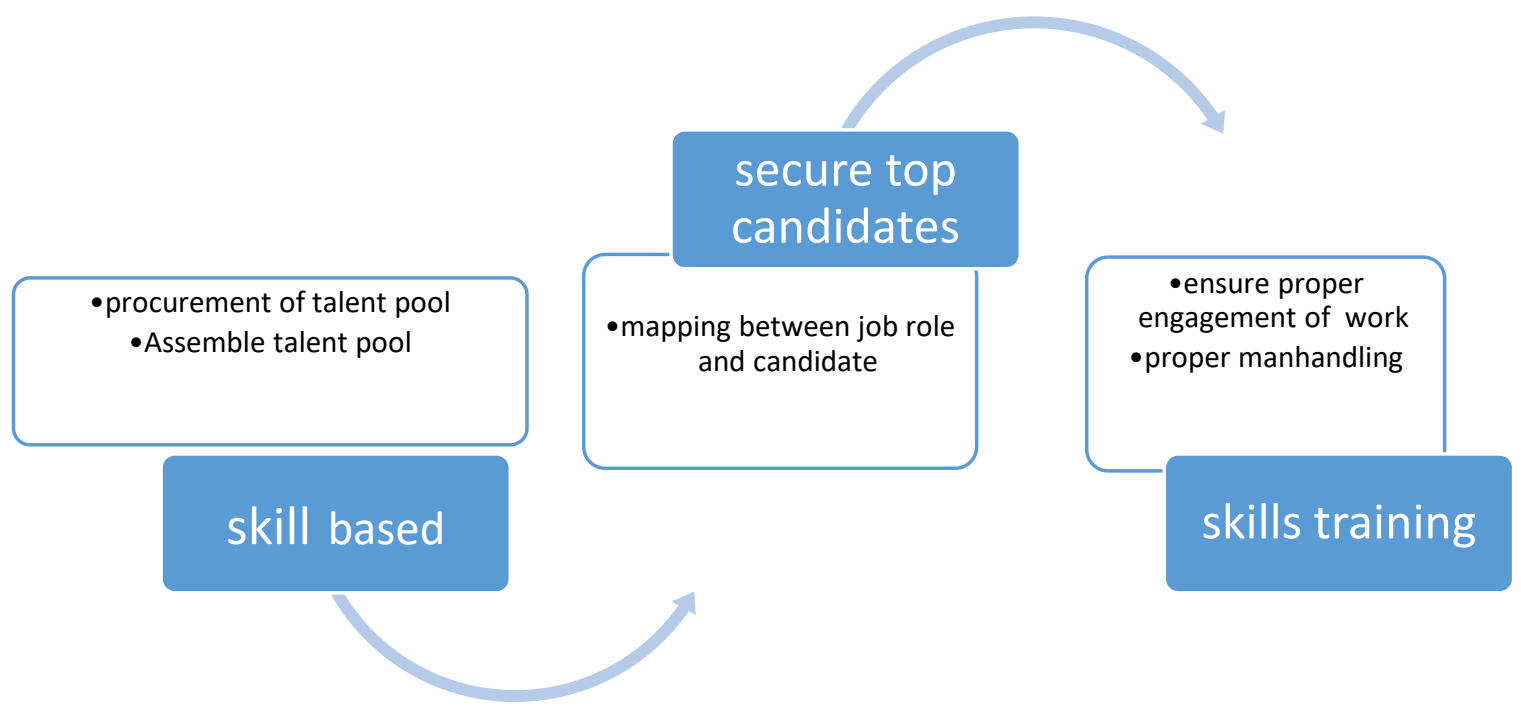

Figure 1: Recruitment Process suggested by Oracle Taleo

Employee retention is a modern technology and aggressive business environment. Organizations with continuous change are not only disturbing the system but also the employees working in it. In order to make the most of organizational competence and for best possible utilization of the resources, human assets must be managed properly. Human resource management plays a very important role in this respect. It is accountable on how recruits are taken care of in the organization. Employee retention is a fundamental issue and challenge to all the organizations nowadays. There were numeral factors which encourage the employees to stay or leave the organization. It could be external factors or internal factors or joint effect of both. Human resource implications count a lot in this regard. It is the demand of the hour that HR managers must observe the requirements of the employee and then expand the retention strategies. A single strategy will not fit to all as different individuals have different priorities. HR professionals have to face the vital challenge to keep talented employees for a longer period. 
Employee retention is very serious in extensive terms of health of any organization.

When an organization fails to keep its talented employee it imprints a negative impact on advancement, customer contentment, knowledge gain in the past years and on the productivity and profitability of the organization. Moreover, replacement theory adds cost to the organization.

\section{Statement of Problem}

Over the years staff turnover has taken a crucial turn in HR concern and practices. The situation of employee retention has become a universal matter and top management people are working around to find new strategies. The researcher would try and evaluate how using these different strategies organisations are striving hard to recuperate with this situation.

\section{Research Questions and Objectives}

Through secondary sources, the purpose of the study was to find answers for the following questions in order to help understand the effectiveness and efficiency of these strategies and also, to recommend any changes if required;

1) What has been the reason for growing issue of retention for past 2-3 years?

2) What planned strategies can be put into exercise to endorse retention?

3) How can employers plan responsibilities to make feel employee engaged in their work place?

4) What implications has employee turnover on daily workings of an organisation?

5) What existing employees' recommend helping reduce employee retention?

\section{Importance of Study}

This study will help top management take improved decision related to recruitment along with breeding new ideas on how to keep performers through inducement programs and creating employee engagement. With fading of employee turnover issue organization's general culture would improve and also cost allocated with turnover will lessen which would be an added advantage for the organisation.

\section{Methodology}

The methodology used for this study is using both primary and secondary sources through various literature, papers, articles available on internet, company editorials of recent times. The quantitative study conducted through questionnaires was circulated amongst regular employees of 30 in numbers from IT industry, manufacturing industry and service industry. To gain an experience on their outlook towards job dissatisfaction, relation with managers and supervisors, compensation benefits.

In survey questionnaires it consisted of 11 questions with an option to add comments at the bottom.the questions used for surveying tool was adapted from K.M Surji (2013) The Negative Effect and Consequences of Employee Turnover and Retention on the Organization and Its Staff. The questions were as follow: 
(Strongly Agree / Agree / Strongly Disagree / Disagree)

1) I recognize the long-term goals of the organization

2) My job is very important to me

3) My direct supervisor has strong interpersonal relations skills

4) Communication is encouraged in this organization

5) This organization has a recognition and appreciation program

6) Development opportunities have been offered to you

7) I am pleased with the work I carry out

8) There is job security with this organization

9) Training is provided within this company

10) Staff members are treated with admiration and respect

11) You are pleased with your compensation and benefits

\section{Findings}

1) Clear knowledge about long-term goals of my company

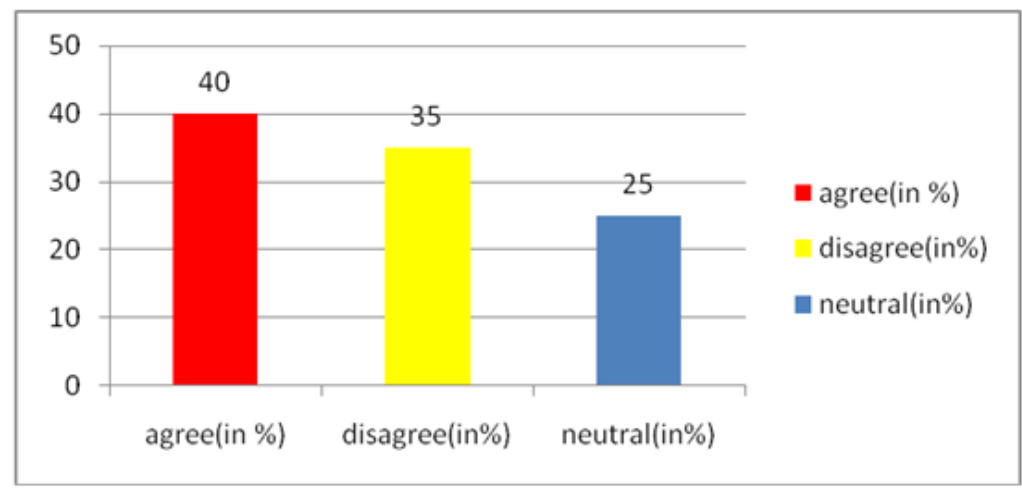

\section{Interpretation of Data}

From the graph it is very clear that employees are still very unclear about organisational objectives and it is the task of management to detail them about company's goal, its aspirations and how employees clubbing together will help them achieve their target.

2) My job is important

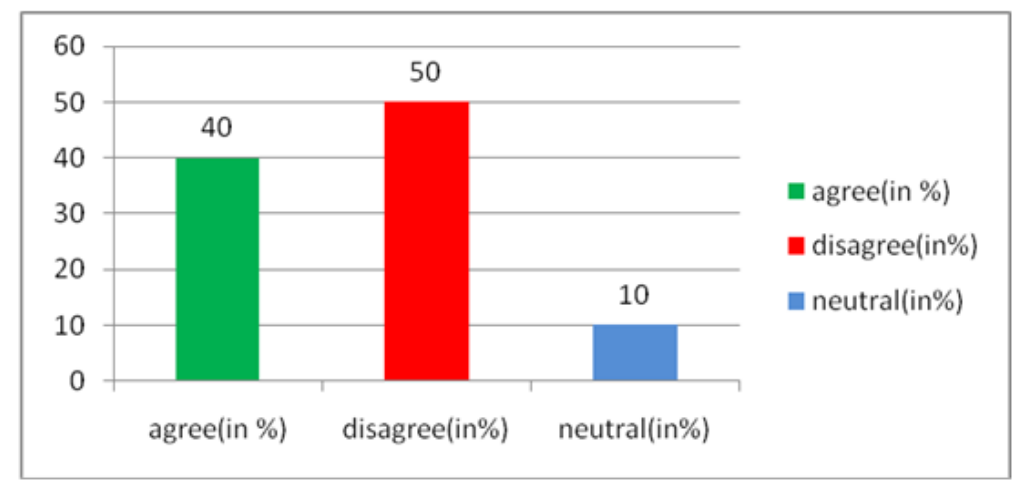




\section{Interpretation of Data}

The results in this graph is very disappointing as the percentage of people considering their job is not important is pretty high which depicts a clear picture of management failing to disengage employees; thus, leading to lack of organisational commitment and questionning integrity.

3) Relationship with superiors

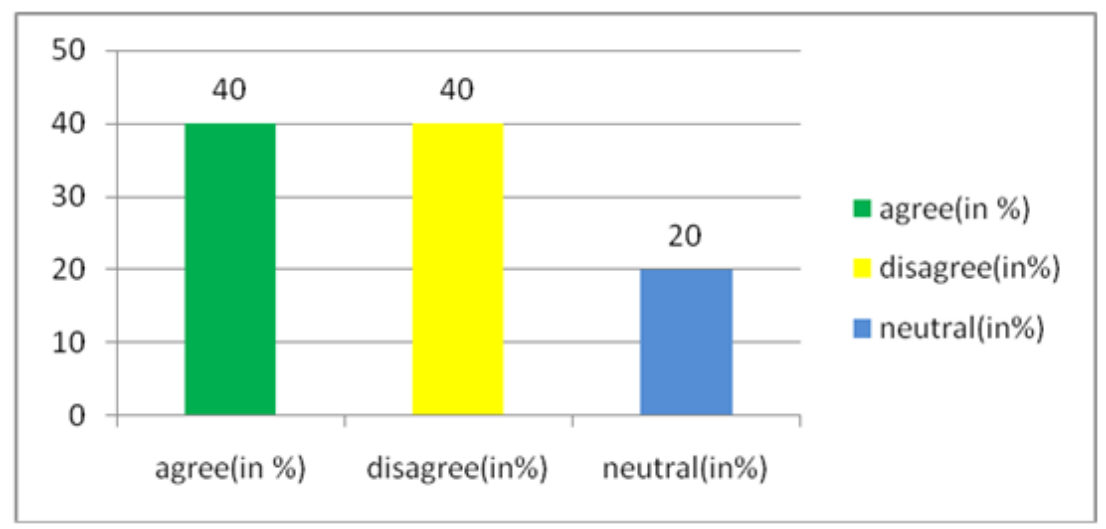

\section{Interpretation of Data}

The graph results are alarming in this aspect. It is the time for management people to realize that human relations have a pivotal role to play when considering organisation as a team. The relation between employer and employee should be well-tuned as it becomes easy for the employer to manage his team and use employee's emotion towards his work in a positive way.

4) Job satisfaction

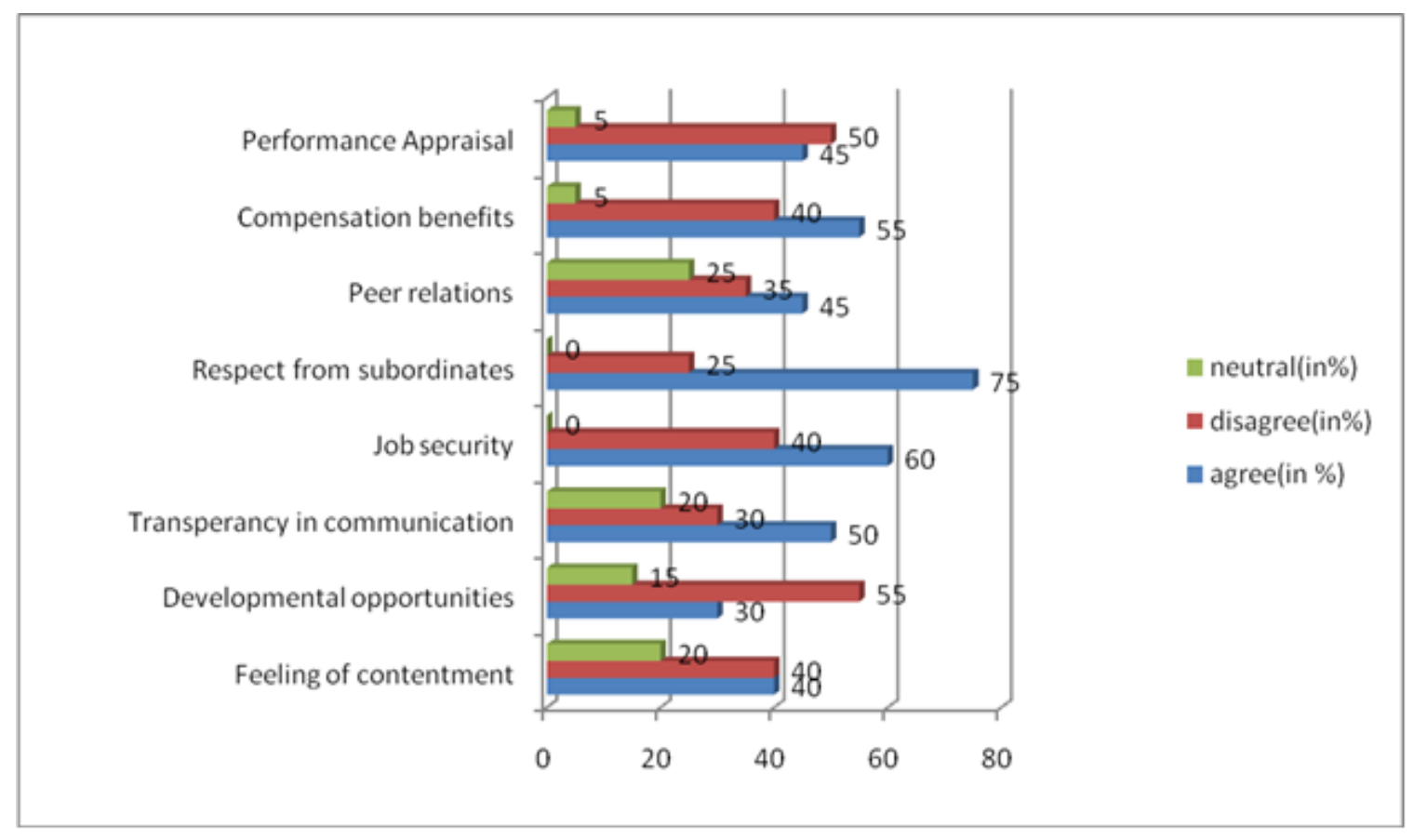




\section{Interpretation of Data}

Through this graph it was easy to understand as a researcher that in contemporary organisation a drastic change in compensation benefits has taken place, leading to increase in satisfactory group of people. The response from respondents was majorly oriented towards emotional turbulence an employee might go through in his workplace like job security, developmental opportunities, feeling of contentment, peer relation if it is creating peer pressure and most importantly performance appraisal system. All these factors are elements of lack of job engagement and failure in man power planning.

Hence, to improve scenario management of some companies have adopted some strategies like:

1) Recognising employee contribution through awards or pay benefits

2) Virtual training processes have been introduced so that employees can train and develop themselves at their own ease of time.

\section{Conclusion and Recommendation}

But as employers and being apart of top management they must observe if each manpower is being utilised optimally; if anyone is excessively burdened with job and the other one is idle. This is not an ideal case and a true example of lack of employee disengagement. This could be a prime reason for employee attrition.

Companies must practise religiously the process of exit interviews as it generates idea and bring forth the causes behind increasing attrition.

A healthy working condition is indeed the first requirement of any employee, so it is mandate for top management to create a work friendly environment, improve work-culture and try to reduce peer pressure along with improvement in relations with superior. Certain companies in IT sectors have introduced the outbound training or other management games to enhance intermingling amongst employees.

\section{References}

[1] Fitz-enz, J. (1990) Getting and Keeping Good Employees. In Personnel, 67, 25-29.

[2] Walker, J.W. (2001) Zero Defections? Human Resource Planning, 24, 6-8.

[3] Brown, L.K., Schultz, J.R., Forsberg, A.D., King, G., Kocik, S.M. and Butler, R.B. (2002) Predictors of Retention among HIV/Haemophilia Health Care Professionals. General Hospital Psychiatry, 24, 48-54. http://dx.doi.org/10.1016/S0163-8343(01)00172-4

[4] Andrews, D.R. and Wan, T.T. (2009) The Importance of Mental Health to the Experience of Job Strain: An Evidence- Guided Approach to Improve Retention. Journal of Nursing Management, 17, 340-351. http://dx.doi.org/10.1111/j.1365-2934.2008.00852.

[5] Ghapanchi, A.H. and Aurum, A. (2011) Antecedents to IT Personnel's Intentions to Leave: A Systematic Literature Review. Journal of Systems and Software, 84, 238-249. http://dx.doi.org/10.1016/j.jss.2010.09.022

[6] Allen, D.G. and Shanock, L.R. (2013) Perceived Organizational Support and Embeddedness as Key Mechanisms Connecting Socialization Tactics to Commitment and Turnover among New Employees. Journal of Organizational Behaviour, 34, 350-369. http://dx.doi.org/10.1002/job.1805 
[7] Bidisha, L. D and Mukulesh, B. (2013) Employee Retention: A Review of Literature. Journal of Business and Management, 14, 8-16.

[8] SIMHAN, T. R. (2014, February 26). Attrition on the rise in IT firms. Retrieved July 09, 2016, from Manjunatha, V., \&Nanjegowda, H. (2016, January).

http://www.thehindubusinessline.com/infoEMPLOYEE ATTRITION Management in tech/attrition-on-the-rise-in-it-firms/article software companies-a conceptual study. Journal of 5730053.ece

[9] Indian IT Sees High Attrition As Market Rebounds. (2014, increased attrition rate. February 27). Retrieved July 09, 2016, from While on other hand the factors "Job Satisfaction" and http://www.cxotoday.com/story/indian-it-sees- "Sociable Organizational Practice" were found to positively high-attrition-as-market-rebounds/

[10] S., Asthana. (2014). High attrition not always a sign of IT industry growth, finds study. doi:September 8,2014.Retreived March 21,2019 from www.business-standard.com/article/companies/high-attrition-not-always-a-sign-of-it-industrygrowth-finds-study-114090800315_1.html

[11] Mita, M., Aarti K. and Ravneeta, D. (2014) Study on Employee Retention and Commitment. International Journal of Advance Research in Computer Science and Management Studies, 2, 154164.

[12] K. M., Surji. (2013). The Negative Effect and Consequences of Employee Turnover and Retention on the Organization and Its Staff. European Journal of Business and Management, Vol.5(No.25), $52-65$

[13] Naqvi, S.M.M.R. and Bashir, S. (2015) IT-Expert Retention through Organizational Commitment: A Study of Public Sector Information Technology Professionals in Pakistan. Applied Computing and Informatics, 11, 60-75. http://dx.doi.org/10.1016/j.aci.2011.11.001

[14] Christeen, G. (2015) Retaining Professional Workers: What Makes Them Stay? Employee Relations, 37, 102-121. http://dx.doi.org/10.1108/ER-10-2013-0151

[15] Website references https://docs.oracle.com/cloud/18a/taleo/OTRCG/OTRCG.pdf

\footnotetext{
*Corresponding author.

E-mail address: archita.banerjee@ rediffmail.com
} 